\title{
Preface to the Special Issue on Stable Isotopes and Geochemistry of Ground Ice
}

Ground ice, defined as all types of ice in freezing or frozen ground (van Everdingen, 1998), has been a focus of periglacial research for many decades. Within non-glaciated cold-climate environments, ground ice is formed as a sink of water in the hydrological cycle, but it may become a source during long-term climate warming. Ground ice formation and loss involve the processes of freezing, melting and sublimation, processes which can be studied using stable isotopes.

This $P P P$ special issue documents the state-of-the-art in the use of stable water (oxygen and hydrogen) isotopes in ground ice research and describes new approaches, which may lead to substantial advances in permafrost science. The idea of the special issue was developed during meetings of the International Permafrost Association (IPA) working group (WG) on Isotopes and Geochemistry of Permafrost co-chaired by Ron Sletten and Hanno Meyer. The WG initially existed from 2003 to 2008 and comprised more than 35 members. The key objectives of the WG were: (1) to promote application of isotope and geochemical methods in permafrost research; (2) to identify the major gaps in knowledge for successful application of isotopic and geochemical methods in permafrost studies; (3) to identify and bring together persons and groups working actively in this kind of research; (4) to facilitate communication with other individuals and programmes involved in isotope and geochemical investigations in polar regions; and (5) to promote archiving and dissemination of data sets. During the Ninth International Conference on Permafrost in Fairbanks, Alaska, a two-year extension of the WG was approved with the goal of producing this special issue. The WG members were asked to submit abstracts in the broad domain of isotope research in permafrost and more than 15 were received from authors in a range of countries. Based on the submissions, it was decided that the special issue would focus primarily on water isotopes in ground ice. Most of the manuscripts were pre-reviewed by the co-chairs, and after revision, were submitted to $P P P$ for the normal review process.

This special issue contains eight papers dealing with different aspects of permafrost research based on, or involving, stable water isotopes $\left(\delta^{18} \mathrm{O}\right.$ and $\left.\delta D\right)$. Studying permafrost as a cold-region phenomenon involves all types of stable isotope fractionation at the phase transitions of water, especially freezing and melting processes, but also evaporation and condensation. To answer specific questions, such as mechanisms of infill of frost cracks, stable isotope data may need to be combined with other methods (e.g. the geochemistry of occluded gases).

In the first contribution of this issue, Fred Michel gives an overview of the knowledge about ground ice in northern Canada - a region known for its wealth of different periglacial landforms and associated ground ice types. Two contributions, by Denis Lacelle and co-authors and Michael Fritz and co-authors, involve theoretical as well as field data, tackling the discrete problem of understanding the (re)freezing of water by stable isotope methods to assess the genesis of massive ground ice bodies (with a focus on the Canadian Arctic). Both papers recommend that stable water isotope studies are supported by additional tools (e.g. hydrochemistry, entrapped gases in the ice). A paper by Marina Leibman and co-authors also deals with genetic aspects of tabular massive ground ice (in the Russian Arctic) but involves sulfur and carbon isotope methods. The paper by Mélanie St Jean and co-authors combines stable water isotopes with other methods such as crystallography, gas composition and hydrochemistry in a novel way to explore the (climatic) significance of stable isotope signals in ice wedges. Rossana Raffi and Barbara Stenni present the first stable isotope data from ice wedges in Antarctica indicating that sublimation processes control the formation of ice in wedges in this region. Contributions by Thomas Opel and others, and by Irina Streletskaya and others, use stable water isotopes in ice wedges for palaeoreconstruction of winter temperatures in different regions of Siberia (Yamal Peninsula, Dmitrii Laptev Strait). Ice wedges are considered as suitable permafrost archives for stable isotope-based palaeoclimate reconstruction, which may be used similarly to glacier ice interpretation when certain boundary conditions (e.g. age assessment, atmospheric moisture source) are fulfilled.

This special issue involves work from North American, European and Russian researchers and tackles many of the research questions that can be addressed using stable isotopes (often combined with other methods), mostly relating to genetic aspects and palaeoclimatic reconstructions. The studies involve different types of massive ground ice over varying time-scales (from recent studies back to the Pleistocene) from the Russian and North American Arctic as well as from Antarctica. The variety of topics, locations and authors demonstrates the potential of stable water isotopes 
and associated techniques to address fundamental questions about the origin and fate of ground ice and thereby to contribute to permafrost science.

\section{ACKNOWLEDGEMENTS}

As organisers of this PPP special issue, we would like to thank all contributing authors. We are also grateful to the numerous reviewers, who provided critical and constructive suggestions that improved the manuscripts and brought them into the shape and scientific level of this PPP special issue. Both the past and present IPA presidents, Dr Jerry Brown and Professor Hans-W. Hubberten, are thanked for supporting the WG as well as this special issue.

\section{REFERENCE}

van Everdingen RO (ed). 1998. Multi-language Glossary of Permafrost and Related Ground Ice Terms. International Permafrost Association: 78pp.

H. Meyer Alfred Wegener Institute for Polar and Marine Research, Research Unit Potsdam, Potsdam, Germany

R. S. Sletten

University of Washington, Seattle, Washington, USA

Published online in Wiley Online Library (wileyonlinelibrary.com)

DOI: $10.1002 /$ ppp.718 